\title{
Large scale assessment of the production process and rice yield gap analysis by comparative performance analysis and boundary-line analysis methods
}

\author{
Ahmad Gorjizad, ${ }^{1}$ Salman Dastan, ${ }^{2}$ Afshin Soltani, ${ }^{3}$ Hosein Ajam Norouzi ${ }^{1}$ \\ ${ }^{1}$ Department of Agronomy, Gorgan Branch, Islamic Azad University, Gorgan; ${ }^{2}$ Agricultural Biotechnology \\ Research Institute of Iran, Karaj; ${ }^{3}$ Department of Agronomy, Gorgan University of Agricultural Sciences \\ and Natural Resources, Gorgan, Iran
}

\begin{abstract}
To reduce the yield gap, specifying yield constraints in a particular area is necessary. A complete yield gap assessment method must provide information regarding potential yield, actual yield, and causes of the gap and their importance. Therefore, documenting the production process to explain crop management factors in each area is very important. The objective of the study was to perform a rice yield gap analysis by using comparative performance analysis (CPA) and boundary-line analysis (BLA). Data were gathered from about 100 paddy fields in Neka, eastern Mazandaran province, one of the major rice producing regions in Iran, in 2015 and 2016. All agricultural practices from nursery preparation to harvest have been recorded for improved rice cultivars. CPA focuses on the ability to estimate potential yield and the reason for a yield gap. Boundary lines were fitted to the edge of the data cloud of crop yield versus management variables in data from paddy fields monitoring. The documenting analysis shows that the range of paddy yield in 100 fields varied from 6100 to $8200 \mathrm{~kg} \mathrm{ha}^{-1}$. Potential yields were $9241 \mathrm{~kg} \mathrm{ha}^{-1}$ for CPA method, and $7999 \mathrm{~kg} \mathrm{ha}^{-1}$ for BLA method. Furthermore, yield gap predicted $2047 \mathrm{~kg} \mathrm{ha}^{-1}$ for CPA method and $874 \mathrm{~kg} \mathrm{ha}^{-1}$ for BLA method. In BLA, the average relative yield and relative yield gap of the 13 investigated variables were $89.75 \%$ and $10.25 \%$ respectively. These results show the importance of each management factor in yield gap. It was concluded that CPA and BLA as applied in the
\end{abstract}

Correspondence: Salman Dastan, Agricultural Biotechnology Research Institute of Iran (ABRII), Karaj, Iran.

Tel.: +98.9111552587.

E-mail: dastan@abrii.ac.ir

Key words: Actual yield; attainable yield; crop management; potential yield; relative yield.

Received for publication: 22 December 2017.

Revision received: 31 July 2018.

Accepted for publication: 13 September 2018.

(C) Copyright A. Gorjizad et al., 2019

Licensee PAGEPress, Italy

Italian Journal of Agronomy 2019; 14:1174

doi:10.4081/ija.2019.1174

This article is distributed under the terms of the Creative Commons Attribution Noncommercial License (by-nc 4.0) which permits any noncommercial use, distribution, and reproduction in any medium, provided the original author(s) and source are credited. study is a cheap and simple method that, without the need for expensive experimentation, is able to detect yield gap and its causes in a district. From these results, it can be said that the calculated yield gap is close to the definition given for the utilised yield gap and shows the difference between the actual yield and attainable yield in relation to the environmental conditions of the region.

\section{Introduction}

Rice (Oryza sativa L.), the most important cereal in the world, fulfils one-third of the food requirement of the world population. It provides about 700 calories per person, and is consumed mostly by people, residing in developing countries (Farooq et al., 2009). Rice is an important crop in Iran, ranking second to wheat as a staple food. Rice has gradually begun to occupy a predominant position in the agricultural economy of the Mazandaran province in Iran. Based on global statistics, rice production is about 750 million tons in the world (FAO, 2016). Presently, the rice cultivation area in Iran was about 550 thousand hectares. In Iran, the Mazandaran province ranks first in terms of rice cultivation area (230 thousand hectares) and rice production. Moreover, the rice cultivation area in the Neka region is about 10,000 hectares equivalent to $4.5 \%$ of the total paddy field area in the Mazandaran province (Ministry of Jihad-e-Agriculture of Iran, 2016).

The problems and challenges of the rapidly increasing world population, global climate change, shortages of water suitable for irrigation and degradation of agricultural land are leading to an increase in the demand to improve grain production from rain-fed arable lands. Specific challenges include the estimation of the size and thus the value of the yield gap, identification of the factors limiting current average production, and designing of profitable remedial strategies for a range of agro-ecological regions. One promising way to increase crop production is by closing the gap between yield achieved on the farmer's field and that, which can be achieved by using the best-adapted crop varieties, and best crop and land management practices for a given environment (van Ittersum et al., 2013). Other researchers, through a revision study of completed research works worldwide, also carried out the analysis of cropping systems for increasing resistance (Reidsma and Jeuffroy, 2017). Moreover, yield gap analysis in agricultural plants are vastly investigated in the world, they can be situated into worldwide level (van Ittersum et al., 2013); national level (Hochman et al., 2013) and regional level (Liu et al., 2016). Also, more research is conducted on three main cereals like wheat, rice and corn, which are focused on providing the main component of human food (Beza et al., 2017). Some other studies have been conducted for rice yield gap analysis in conventional and organic cropping systems in the Mediterranean (Delmotte et al., 2011) to 
determine the effective factors on yield variation of flooded rice in southern-central Benin (Tanaka et al., 2013), define rice yield recession factors in flooded planting systems in the Senegal river valley (Tanaka et al., 2015), simulate rice yield gap in the world (Mueller et al., 2012), and determine yield gap in rice flooding system in China (Xu et al., 2016) and rice yield gap analysis by making models in Philippines (Silva et al., 2017).

Exploitable rice yield gaps are often caused by various factors, which may be classified as physical, biological, agronomic, socioeconomic and institutional constraints. These can be effectively improved through participatory approach in action. The narrowing of the yield gap is not static but dynamic with the technological developments in rice production, as the gaps tend to become enlarged with increase in potential yield due to the use of improved cultivars. The narrowing of rice yield gap requires integrated and holistic approaches, including appropriate concept, policy intervention, understanding of the farmers' actual constraints in achieving high yield, deployment of new technologies and integrated crop management promotion, adequate input supplies and field credit, and strengthening of research and extension and the linkages between them. If even one of these components is missing or weak, the narrowing of the yield gap in a particular rice production area cannot reach its full potential. Due to its complexity, there are different points of view regarding the possibility of narrowing yield gaps as a tool for increasing rice production. In fact, the causes of rice yield gaps differ widely from season to season, country to country and/or even from location to location within a country or region. It is therefore essential to consider the yield gap of rice in the local climate and ecosystem. Therefore, the aim of this study was to document the production process and estimate the yield gap in paddy fields in the north of Iran by CPA (Hocking, 1976), and BLA (Webb, 1972; Makowski et al., 2007).

\section{Materials and methods}

\section{Description of the site}

This experiment was carried out in the Neka area, east of the Mazandaran province. Neka city is located in the northern part of the Alborz Mountains range and the south of the Caspian Sea in northern Iran. The experimental region is geographically situated at $36^{\circ} 39^{\prime} \mathrm{N}(707702 \mathrm{~m} \mathrm{E})$ and $53^{\circ} 19^{\prime} \mathrm{E}$ (4058571 $\mathrm{m} \mathrm{N}$ ).

Based on the temperature, rain, and topography of the region, this province is divided into two climate Caspian mild weather and mountain weather. This research covers both climates. Local weather data during the rice-growing period were collected daily from the synoptic meteorological station nearest to the paddy fields (Table 1). Srad_calc and PP_calc programs can also be downloaded from https://sites.google.com/site/cropmodeling/ home.

\section{Data collection}

All the agricultural practices in this research, from the primary plough and nursery preparation to harvest, were recorded by paddy field monitoring. For estimating yield gap, all agricultural practices were recorded, from nursery preparation to the harvesting stage, in 100 paddy fields in the Neka region situated in the Mazandaran province via paddy field monitoring in 2015 and 2016. All paddy fields cases pertain to improved rice cultivars. The characteristics of rice cultivars are shown in Table 2. The method of each agricultural practice in the paddy fields was determined for each of the phases of preparing soil, transplanting, cultivating, and harvesting. For each crop, the detected information were frequency and time of tillage operations (e.g. plough and disk cultivation), sowing date,

Table 1. Climatic parameters in the survey (2015-2016) and in the long-term period (2001-2016) in Neka region.

\begin{tabular}{|c|c|c|c|c|c|c|c|c|c|c|c|c|c|c|}
\hline \multirow[t]{2}{*}{ Month } & \multicolumn{2}{|c|}{$\begin{array}{l}\text { Average min. } \\
\text { Temp. }\left({ }^{\circ} \mathrm{C}\right)\end{array}$} & \multicolumn{2}{|c|}{$\begin{array}{l}\text { Average max. } \\
\text { Temp. }\left({ }^{\circ} \mathrm{C}\right)\end{array}$} & \multicolumn{2}{|c|}{$\begin{array}{l}\text { Evaporation } \\
\text { (mm/month) }\end{array}$} & \multicolumn{2}{|c|}{$\begin{array}{c}\text { Rain } \\
\text { (mm/month) }\end{array}$} & \multicolumn{2}{|c|}{$\begin{array}{l}\text { Mean relative. } \\
\text { humidity (\%) }\end{array}$} & \multicolumn{2}{|c|}{$\begin{array}{c}\text { Mean } \\
\text { sunshine hours }\end{array}$} & \multicolumn{2}{|c|}{$\begin{array}{c}\text { Solar radiation } \\
\left(\mathrm{MJ} \mathrm{m}^{-2} \mathrm{~d}^{-1}\right)\end{array}$} \\
\hline & 2015 & 2016 & 2015 & 2016 & 2015 & 2016 & 2015 & 2016 & 2015 & 2016 & 2015 & 2016 & 2015 & 2016 \\
\hline April & 9.5 & 10.8 & 19.5 & 18.6 & 71.8 & 63.2 & 98.7 & 99.3 & 76 & 77 & 157.7 & 123.6 & 14.7 & 13.5 \\
\hline May & 15.8 & 16.4 & 25.2 & 24.8 & 115.9 & 85.9 & 27.0 & 41.4 & 77 & 78 & 168.8 & 140.9 & 17.0 & 15.9 \\
\hline June & 19.2 & 19.9 & 28.6 & 27.8 & 154.4 & 121.8 & 23.7 & 24.6 & 76 & 80 & 252.2 & 232.8 & 22.2 & 21.1 \\
\hline July & 22.2 & 22.3 & 31.4 & 30.7 & 169.4 & 130.2 & 59.4 & 39.6 & 75 & 79 & 238.0 & 203.0 & 21.3 & 19.7 \\
\hline August & 22.6 & 22.5 & 33.5 & 33.1 & 193.9 & 142.3 & 6.7 & 11.4 & 73 & 76 & 269.5 & 232.5 & 21.9 & 20.2 \\
\hline September & 21.2 & 21.6 & 32.0 & 31.0 & 156.6 & 113.9 & 99.3 & 88.5 & 71 & 65 & 240.5 & 193.0 & 18.6 & 16.5 \\
\hline Mean 15 years & 18.3 & 18.5 & 25.2 & 25.2 & 147.6 & 147.6 & 89.0 & 89.0 & 73.5 & 73.5 & 208.8 & 208.8 & 19.5 & 19.5 \\
\hline
\end{tabular}

Table 2. Description of name, origin and other characteristics of rice cultivars in the experiment.

\begin{tabular}{lccc} 
Cultivar* & Maturity condition & Paddy yield potential & Baking quality \\
Shiroodi & Late maturity & High yield & Low \\
Neda & Late maturity & High yield & Medium \\
\hline Fajr & Late maturity & High yield & Low \\
Ghaem & Late maturity & High yield & Low \\
\hline Khazar & Medium maturity & Medium yield & Medium \\
Nemat & Late maturity & High yield & Low \\
\hline
\end{tabular}

*Investigated Iranian improved rice cultivars were semi-dwarf, tolerant to stress. 
seeding date, transplanting date, seeding rate, seedling age, plant density, frequency and the amount of nitrogen fertiliser, the amount of phosphorus $\left(\mathrm{P}_{2} \mathrm{O}_{5}\right)$ and potassium $\left(\mathrm{K}_{2} \mathrm{O}\right)$ fertilisers, irrigation frequency and regimes, time and frequency of weed, disease and pest controls and harvesting date. Time of operations (e.g. transplanting date) was considered as day since 23 April.

The paddy fields were selected with the help of local experts to represent a wide range of situations. All the management practices/inputs (variables) were monitored and recorded without interfere with farmer operations. The manner of identifying farms covers all main production methods. Then, information pertaining to farm management was collected. For data collecting, all agricultural variables were first separated. In total, paddy fields were different with respect to field area, production operations, inputs used and crop yield were evaluated over the growing seasons from nursery preparation to harvest. At the end of the growing season, the actual yield was registered.

\section{Estimation of yield gap}

\section{Comparative performance analysis}

Multiple using stepwise regression (Hocking, 1976) was employed to identify factors that explained variation in rice yields from the 150 independent variables. In order to determine the yield model (production model), the relationships between all variables were measured and the yield was evaluated using the regression method. The average paddy yield was calculated by placing the observed average variables (Xs) in the fields under study in the yield model. Thereafter, by putting the best-observed value of the variables in the yield model, the maximum obtainable yield was calculated. The difference between these two is considered as the yield gap. The difference between the products of the average observed value of each variable with its coefficient and the product of the best observed value for the same variable with the coefficient of the same variable presents yield gap value for that variable. The ratio of yield gap for each variable to the total yield gap shows its contribution in creating the yield gap and is presented in percentage. The analysis has been performed by SAS software, version 9.1, were used for the analysis (Hocking, 1976; SAS, 2008).

\section{Boundary line analysis}

The main steps adopted for the yield gap assessment using BLA in a specific region/area were: i) selection of farms in the study area. If the study area is large (as it is in the present research) it can be divided to several rather homogenous sub-areas based on climate, soil and/or management system differences. To obtain satisfactory results, a wide range of farms/fields with very different practices/inputs for each of sub-areas, is required; ii) gathering information on management and inputs as the farmers apply them. Only the practices that are under control of the farmers are included. As many as possible agricultural practices need to be included; iii) application of BLA to the gathered data and interpret the results. There is no agreed protocol for application of BLA. In general, some points from the outer edge of the data cloud are chosen and a line is fitted to them. This boundary line specifies the highest attainable yield or the maximum yield under the influence of different levels of a certain variable.

Three general steps can be considered to obtain the boundary line as below (Shatar and McBratney, 2004; Makowski et al., 2007; Patrignani et al., 2014): i) examining the scatter plot of data: a scatter plot (XY chart) should be prepared with crop yield as dependent variable and one selected management variable (e.g. transplanting date or number of seedling per hill) as independent variable. This step visualises the data cloud and facilitates selecting a proper function to be fitted to the edge of data cloud; ii) selection of the data points from the edge of data cloud to be used in curve fitting: this can be done simply by eye or by one of the advanced statistical methods. There are some statistical methods to objectively choose the outer points for curve fitting or directly fit a line to the outer edge of the data cloud (e.g. Milne et al., 2006). For more information in this regards, readers can refer to: Schnug et al. (1996); Kitchen et al. (2003); Shatar and McBratney (2004); Makowski et al. (2007); Huang et al. (2008); Riffel (2012); Tasistro (2012); Banneheka et al. (2013); and Patrignani et al. (2014). For simplicity, in the present study is the selection of the data points from the outer edge of the data by eye and then fitting appropriate function to the points. Such simple methods are also helpful and effective as demonstrated by French and Schultz (1984); iii) the final step is to fit a function to the data points obtained from the second stage. This stage results in a model that explained the response of maximum yield to different levels of the independent variable under examination.

In the BLA method, yield gap (Yg) is calculated as the difference between potential yield (Yp) and average farmers yield (actual yield) (Ya). The relative yield is estimated as:

$[\mathrm{Ya} / \mathrm{Yp} \times 100]$

which indicates how far or close farmers' yields are to Yp. Relative yield gap is obtained as:

$[\mathrm{Yg} / \mathrm{Yp} \times 100]$

as per Soltani et al. (2016). SAS software was used to fit the selected functions (SAS, 2008).

\section{Results}

\section{Estimating yield gap by comparative performance analysis}

\section{Production model}

The results of step-by-step regression are presented in Table 3 to determine the most important management variables affecting the yield and production model. In this regression model, the paddy yield per unit area is considered as a dependent variable and other variables such as rapeseed pre-sowing, crop rotation (previous crop), certified seed, seeding date in nursery, $\mathrm{N}$ top-dressing usage, $\mathrm{K}_{2} \mathrm{O}$ usage, $\mathrm{N}$ usage after flowering, and micronutrient foliar application are considered as independent variables, resulting in the final equation. Finally, by using this production equation, the actual yield, the attainable yield, and the share of each variable on yield reduction were determined. Thus, by considering about 150 variables, the model (final regression equation) was selected by stepwise regression with eight independent variables (Table 3 ). The final yield equation is as follows:

$\mathrm{Y}(\mathrm{kg} / \mathrm{ha})=6440-425 \mathrm{X}_{1}+307 \mathrm{X}_{2}+256 \mathrm{X}_{3}-9 \mathrm{X}_{4}+495 \mathrm{X}_{5}+$ $10 \mathrm{X}_{6}+146 \mathrm{X}_{7}+314 \mathrm{X}_{8}$

where $\mathrm{Y}$ : paddy yield $\left(\mathrm{kg} \mathrm{ha}^{-1}\right), \mathrm{X}_{1}$ : rapeseed pre-sowing, $\mathrm{X}_{2}$ : crop rotation, $\mathrm{X}_{3}$ : certified seed, $\mathrm{X}_{4}$ : seeding date in nursery, $\mathrm{X}_{5}$ : $\mathrm{N}$ top- 
dressing, $\mathrm{X}_{6}: \mathrm{K}_{2} \mathrm{O}$ usage per hectare, $\mathrm{X}_{7}: \mathrm{N}$ usage after flowering, and $\mathrm{X}_{8}$ : micronutrient foliar application. In this method, Dummy variable approach is adopted.

\section{Yield limiting factors and estimation of yield gap}

Table 3 shows the independent variables entered in the regression model with their observed statistics. The best model for some variables, including crop rotation, certified seed, $\mathrm{N}$ top-dressing usage, $\mathrm{K}_{2} \mathrm{O}$ usage, $\mathrm{N}$ usage after flowering, and micronutrient foliar application with positive effect, was selected. Rapeseed presowing and seeding dates in nursery variables had a negative effect and small amount of these variables were selected for best amount. Therefore, the optimal value of these two variables was equivalent to the minimum (Table 3 ). The increase in yield resulting from the difference between the best and the medium state of rapeseed presowing and seeding dates in nursery was 34 and $223 \mathrm{~kg} \mathrm{ha}^{-1}$, respectively, equal to two and $11 \%$. The increase in paddy yield due to the effect of the crop rotation was $111 \mathrm{~kg} \mathrm{ha}^{-1}$ equivalent to $5 \%$ of the total yield increase. The increase in paddy yield related to the effect of using certified seeds and top dressing was 141 and $327 \mathrm{~kg} \mathrm{ha}^{-1}$ respectively, equivalent to $7 \%$ and $16 \%$ of total change in paddy yield. The increase in yield related to the effect of $\mathrm{K}_{2} \mathrm{O}$ usage per hectare and $\mathrm{N}$ usage after flowering was 674 and $324 \mathrm{~kg}$ $\mathrm{ha}^{-1}$ respectively, $33 \%$ and $16 \%$ of total yield increase. The yield gap level of micronutrient foliar application was $214 \mathrm{~kg}$ per hectare or $10 \%$ (Table 1 ). Among the eight variables introduced in the model, the effect of $\mathrm{N}$ top-dressing, $\mathrm{K}_{2} \mathrm{O}$ usage per hectare and $\mathrm{N}$ usage after flowering is remarkable, and a significant part of yield gap in farmers' fields can be compensated by managing these three variables.

Table 3 shows the total yield gap and contribution of each factor in limiting yield. In the yield model, the mean and maximum yields were estimated to be 7194 and $9241 \mathrm{~kg} \mathrm{ha}^{-1}$ respectively, comparable with the average and maximum observed yields (7178 and $8200 \mathrm{~kg} \mathrm{ha}^{-1}$ ) respectively. The total estimated yield gap was $2047 \mathrm{~kg} \mathrm{ha}^{-1}$. This means that there is a gap of $2047 \mathrm{~kg} \mathrm{ha}^{-1}$ between the farmer's actual yields and what they can harvest, which can be eliminated or reduced with better management (Table 3 ). Figure 1A shows the contribution of each variable in the yield gap, along with the actual and potential yields. The actual yield, the calculated potential yield and the yield gap were estimated suggesting that this gap can be compensated. The findings given in

Table 3. Quantifying the rice yield gap and the contribution of each independent variable of the production equation in the comparative performance analysis method.

\begin{tabular}{|c|c|c|c|c|c|c|c|c|c|c|}
\hline \multirow[t]{2}{*}{ Variable } & \multirow[t]{2}{*}{ Units } & \multirow[t]{2}{*}{ Coefficients } & \multicolumn{4}{|c|}{ Variable in model } & \multicolumn{2}{|c|}{ Predicted yield } & \multirow{2}{*}{$\begin{array}{l}\text { Yield gap } \\
\left(\mathrm{kg}_{\mathrm{h}} \mathrm{h}^{-1}\right)\end{array}$} & \multirow[t]{2}{*}{ Yield gap \% } \\
\hline & & & Min. & Mean & Max. & Best & Mean & Best & & \\
\hline Intercept & - & $6440 * *$ & - & - & - & - & 6440 & 6440 & - & - \\
\hline Canola pre-sowing $\left(X_{1}\right)$ & - & $-425^{* *}$ & 0 & - & 1 & 0 & - & 425 & 34 & 2 \\
\hline Crop rotation $\left(\mathrm{X}_{2}\right)$ & - & $307^{*}$ & 0 & - & 1 & 1 & - & 307 & 111 & 5 \\
\hline Certified seed $\left(\mathrm{X}_{3}\right)$ & - & $256^{* *}$ & 0 & - & 1 & 1 & - & 256 & 141 & 7 \\
\hline Seeding date in the nursery $\left(\mathrm{X}_{4}\right)$ & days since 21 & $1-9 * *$ & 0 & 26.11 & 58 & 1 & -232 & -9 & 223 & 11 \\
\hline $\mathrm{N}$ top dressing $\left(\mathrm{X}_{5}\right)$ & number & $495^{* *}$ & 0 & - & 1 & 1 & - & 495 & 327 & 16 \\
\hline K usage $\left(\mathrm{X}_{6}\right)$ & $\mathrm{kg} \mathrm{K}_{2} \mathrm{O} \mathrm{ha}^{-1}$ & $10^{* *}$ & 0 & 32.60 & 100 & 100 & 326 & 1000 & 674 & 33 \\
\hline $\mathrm{N}$ after flowering $\left(\mathrm{X}_{7}\right)$ & number & $146^{*}$ & 0 & 0.78 & 3 & 3 & 114 & 438 & 324 & 16 \\
\hline Foliar application $\left(\mathrm{X}_{8}\right)$ & number & $314^{* *}$ & 0 & - & 1 & 1 & - & 314 & 214 & 10 \\
\hline Paddy yield & $\mathrm{kg} \mathrm{ha}^{-1}$ & - & 6100 & 7178 & 8200 & - & 7194 & 9241 & 2047 & 100 \\
\hline
\end{tabular}

* and ${ }^{* *}$ show the probability at 5 and 1 percent level, respectively.
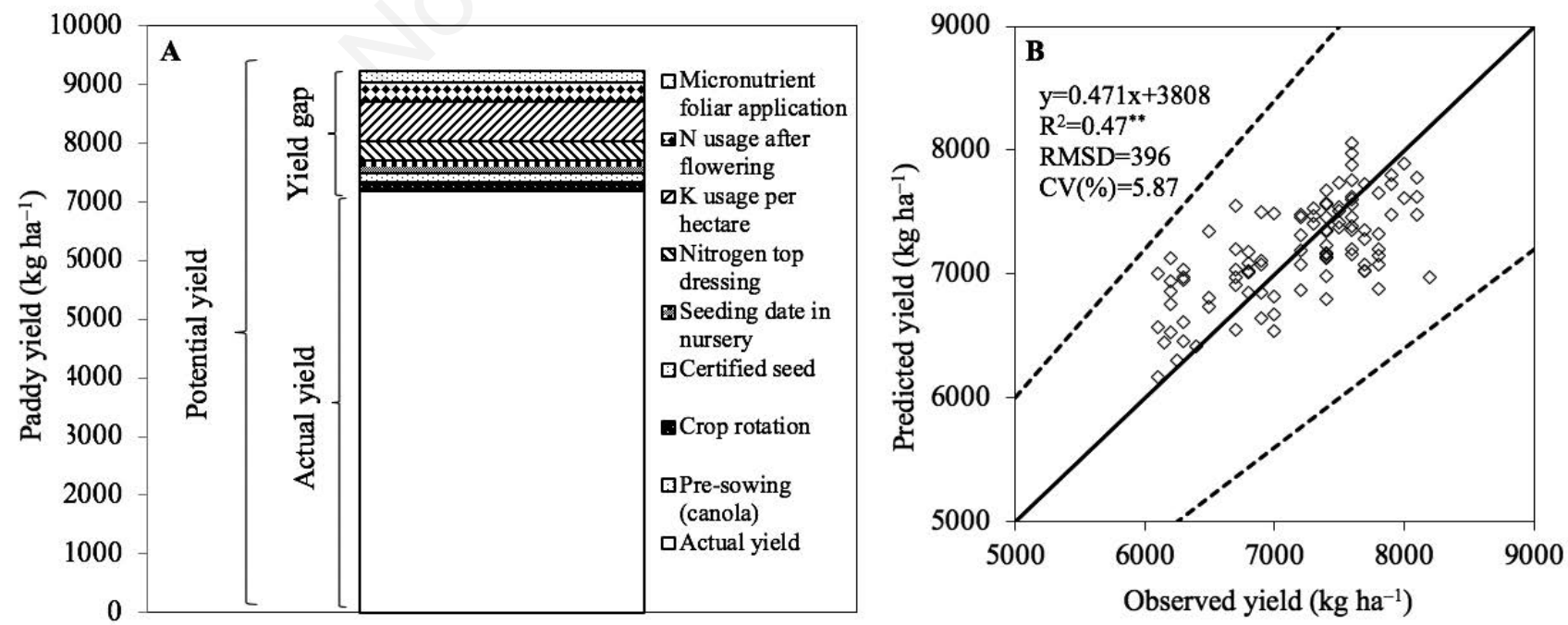

Figure 1. A) The amount of the main constraints of yield gap; B) the relationship between observed and predicted yields. Twenty percent of the differences between predicted and observed yields are shown by segmented lines. 
Figure 1B show the relationship between the actual (observed) yield and the predicted yield. This statistic shows that the accuracy of the model $\left(\mathrm{R}^{2}=0.47^{* *}\right)$ is appropriate and can be used to estimate the yield gap and determine the contribution of each limiting variable (Figure 1B).

\section{Estimating yield gap by BLA method}

In BLA method, a relationship is established between maximum achieved yields $(y)$ and a target variable $(x)$ while other variables are also changing - other variables are not kept constant or optimal. In this method, a line is fitted to the outer edge of the data cloud. This boundary specifies the highest attainable yield (yield potential) or the best yield under the influence of different levels of a certain variable. In this way, it is assumed that (with large data sets) these yields are the highest values in the absence of other limiting factors and all points that fall below of the line have been limited by other factors.

By fitting a line on the upper edge of the data, it was determined that the yield response (dependent variable) follows the independent variables, including seedling number per hill, while $\mathrm{K}_{2} \mathrm{O}$ usage per hectare follows a positive two-piecewise function. Most variables, including seeding date in nursery, seed usage, planting date, seedling age, plant density, $\mathrm{N}$ usage per hectare, and $\mathrm{P}_{2} \mathrm{O}_{5}$ usage per hectare, follow a negative two-piecewise function. However, the variable, which covers pest and diseases problems, follows a linear function with a negative slope and the variable covering plant lodging and weed problems follows a positive linear gradient function. The findings of these variables indicate that the function of the points below the boundary line is limited by other factors. For some management practices/input, it was not possible to fit a boundary line because there was no relationship between the variables and the maximum yields. Therefore, it has been concluded that crop yield is not limited by the variables as they are currently practiced. Variables that we were able to find relationships for them were: seed rate, seeding date in the nursery, transplanting date, seedling age, seedling per hill, planting density, the amount of applied nitrogen (as $\mathrm{N}$ ), phosphorous $\left(\right.$ as $\left.\mathrm{P}_{2} \mathrm{O}_{5}\right)$ and potassium (as $\mathrm{K}_{2} \mathrm{O}$ ) fertilisers and the problem of lodging, pests, diseases and weed (Table 4; Figures 2A-D and 3A-D). These variables are causes of the yield gap and should be considered for the improvement under the current conditions. Figures 2 and 3 present scatter plots of rice yield versus target management variables. Fitted lines in the figures specify maximum yield $\left(\mathrm{Y}_{\mathrm{x}}\right)$ for every given level of the variable under consideration and the horizontal line represent potential yield $\left(\mathrm{Y}_{\mathrm{p}}\right)$. All the data points below the lines mean crop yield has been limited by other variables else the variable under examination (Kitchen et al., 2003).

The average yield in 100 paddy fields was $7178 \mathrm{~kg} \mathrm{ha}^{-1}$ (Table 4). A two-piecewise regression model was fitted as BLA applied to seed rate, seeding date, seedling age and transplanting date (Figure 2A-D). Seed rate varied between 30 and $120 \mathrm{~kg} \mathrm{ha}^{-1}$ across the rice production situations in the province. BLA analysis showed that minimum seed rate of $55 \mathrm{~kg} \mathrm{ha}^{-1}$ was optimal rate for improved rice cultivars in the region and could help farmers to reach potential yield of $7991 \mathrm{~kg} \mathrm{ha}^{-1}$ (Figure 2A). BLA indicated also that $63 \%$ of farmers suffered from yield penalty due to non-optimal seed rate. Regarding the average farmers yield, relative yield gap and yield gap were $10.17 \%$ and $7.61 \%$ of the total for seed rate variable. Thus, farmers reached $90 \%$ of the potential yields by seed usage variable (Table 4). These results indicate that by consuming $55 \mathrm{~kg}$ of seed per hectare, optimal paddy yield is obtained and higher seed consumption results in reduced yield.

A negative two-piecewise function was fitted as BLA applied to seeding date in the nursery (as days since $21 \mathrm{March}$ ) (Figure 2B). BLA showed that yield potential and yield gap were 8952 and 774 $\mathrm{kg} \mathrm{ha}^{-1}(7.25 \%)$ for this variable. Therefore, farmers reached $80 \%$ of the potential yields (Table 4). BLF indicated that to reach these potential yields seeding date in the nursery should be undertaken since 4 May (Table 4). Findings regarding seeding date in nursery show that $25 \%$ of the fields were outside the optimal level. Relative yield gap and a relative yield for seeding date variables was obtained at $9.73 \%$ of $90.27 \%$ respectively (Table 4 and Figure $2 \mathrm{~A}$ ).

The boundary line analysis of transplanting date showed that $12 \%$ of the paddy fields were outside the optimal level.

Table 4. Estimation of potential yield and yield gap of rice with the boundary-line analysis method.

\begin{tabular}{|c|c|c|c|c|c|c|c|c|}
\hline Variable & Unit & $\begin{array}{l}\text { Minimum } \\
\text { optimal } \\
\text { level }\end{array}$ & $\begin{array}{l}\text { Out of } \\
\text { optimal } \\
(\%)\end{array}$ & $\begin{array}{c}\text { Yield based on } \\
\text { optimal level } \\
\left(\mathrm{kg} \mathrm{ha}^{-1}\right)\end{array}$ & $\begin{array}{l}\text { Relative } \\
\text { yield } \\
(\%)\end{array}$ & $\begin{array}{l}\text { Yield gap } \\
\left(\mathrm{kg} \mathrm{ha}^{-1}\right)\end{array}$ & $\begin{array}{l}\text { Relative } \\
\text { yield gap } \\
(\%)\end{array}$ & $\begin{array}{l}\text { Yield } \\
\text { gap } \\
(\%)\end{array}$ \\
\hline Seed rate & $\mathrm{kg} \mathrm{ha}^{-1}$ & 55 & 63 & 7991 & 90 & 813 & 10 & 8 \\
\hline Seeding date in nursery & from 21 March & 25 & 45 & 8952 & 90 & 774 & 10 & 7 \\
\hline Transplanting date & from 21 March & 77 & 12 & 7894 & 91 & 716 & 9 & 7 \\
\hline Seedling age & day & 40 & 14 & 7927 & 91 & 749 & 9 & 7 \\
\hline Seedling & $\mathrm{n} / \mathrm{hill}$ & 4 & 12 & 8000 & 90 & 822 & 10 & 8 \\
\hline Planting density & $\mathrm{n} / \mathrm{m}^{2}$ & 22 & 51 & 8025 & 89 & 847 & 11 & 8 \\
\hline Nitrogen & $\mathrm{kg} \mathrm{N} \mathrm{ha}^{-1}$ & 116.30 & 24 & 8151 & 88 & 973 & 12 & 9 \\
\hline Potassium & $\mathrm{kg} \mathrm{K}_{2} \mathrm{O}$ ha $^{-1}$ & 20 & 16 & 8040 & 89 & 862 & 11 & 8 \\
\hline Lodging problem & number & 1 & 19 & 7990 & 90 & 812 & 10 & 8 \\
\hline Pests problem & number & 1 & 89 & 8190 & 88 & 1012 & 12 & 9 \\
\hline Diseases problem & number & 1 & 84 & 8050 & 89 & 872 & 11 & 8 \\
\hline Weed problem & number & 1 & 6 & 7700 & 93 & 522 & 7 & 5 \\
\hline Mean & - & - & - & 8076 & 90 & 815 & 10 & 100 \\
\hline
\end{tabular}

The average yield in 100 paddy fields was $7178 \mathrm{~kg} \mathrm{ha}^{-1}$. 
Transplanting outside of the intervals was result in yield penalty for the farmers. The harvested yield of the farmers is suffered from nonoptimal sowing date. The minimum optimal value for this variable was June 5 (Table 4). The yield at the optimum level for this variable was $7894 \mathrm{~kg} \mathrm{ha}^{-1}$ with a yield gap of $716 \mathrm{~kg} \mathrm{ha}^{-1}(6.71 \%$ of total). Thus, farmers reached $91 \%$ of the potential yield. Relative yield and relative yield gap under the effect of transplanting date were $90.93 \%$ and $9.07 \%$ respectively (Table 4 and Figure $2 \mathrm{C}$ ).

The minimum optimal rate for seedling age was 40 days. This variable fallowed a positive two-piecewise function, which shows that seedling-aging time of 20-40 days had no negative effect on the yield while the use of seedlings older than 40 days decreased paddy yield (Figure 2D). BLA analysis indicated that $14 \%$ of the farmers suffered from yield penalty due to non-optimal seedling age. Yield potential was $7927 \mathrm{~kg} \mathrm{ha}^{-1}$, with a yield gap of $749 \mathrm{~kg}$ $\mathrm{ha}^{-1}(7.02 \%$ of the total) (Figure 2D). Thus, farmers reached $90 \%$ of the potential yields. Moreover, the relative yield and relative yield gap of seedling age were $90.55 \%$ and $9.45 \%$, respectively (Table 4). Findings of seedling frequency per hill showed that a minimum of four seedlings per hill was required to reach a potential yield of $8000 \mathrm{~kg} \mathrm{ha}^{-1}$, for which yield gap was $822 \mathrm{~kg} \mathrm{ha}^{-1}$ $(7.70 \%)$ and the relative yield was $89.73 \%$. But $12 \%$ of the farmers under the production situation did not apply this number of hill (Figure 3A and Table 4). BLA showed that it was possible for the farmers to reach $90 \%$ of the potential yield with three seedlings per hill (Figure 3A). The results of BLA for planting density variable indicate that the minimum optimal planting density was 22 plants per $\mathrm{m}^{2}$ and $51 \%$ of the fields were outside the optimal level (Table 4). The yield based on the optimal level under this variable effect was $8025 \mathrm{~kg} \mathrm{ha}^{-1}$ with a yield gap of $847 \mathrm{~kg} \mathrm{ha}^{-1}$ (7.33\% of total) (Figure 3B). Thus, farmers achieved $89 \%$ of the potential yield. Furthermore, the relative yield and relative yield gap for planting density were $89.44 \%$ and $10.55 \%$ respectively (Table 4 ).

Using data of paddy yield $v s$ total $\mathrm{N}$ fertiliser, BLA estimated potential yields of $8151 \mathrm{~kg} \mathrm{ha}^{-1}$ and that a minimum $\mathrm{N}$ fertiliser of $116.3 \mathrm{~kg} \mathrm{ha}^{-1}$ was required to reach the potentials (Figure 3C; Table 4). The analysis also revealed that application of $\mathrm{N}$ fertiliser at rates higher than $116.3 \mathrm{~kg} \mathrm{ha}^{-1}$ resulted in yield losses for improved rice cultivars in the region. An average of $24 \%$ of farmers did not use the optimal range. A yield gap estimate from application of BLA to $\mathrm{N}$ related variable was $973 \mathrm{~kg} \mathrm{ha}^{-1}$ (9.11\% of total). Relative yield and relative yield gap for this variable were $88.06 \%$ and $11.94 \%$, respectively (Table 4 ).

When applied to potassium fertilisation, BLA demonstrated that potential yields of $8040 \mathrm{~kg} \mathrm{ha}^{-1}$ was obtainable, corresponding to yield gaps of $862 \mathrm{~kg} \mathrm{ha}^{-1}$ equals $8.45 \%$ (Figure 3D; Table 4). According to the finding, farmers reached $89 \%$ of the potential yield by potassium consumption. The minimum potassium fertiliser required to obtain the potential yields was $20 \mathrm{~kg} \mathrm{~K}_{2} \mathrm{ha}^{-1}$. However, $16 \%$ of farmers did not apply the minimum levels; furthermore,
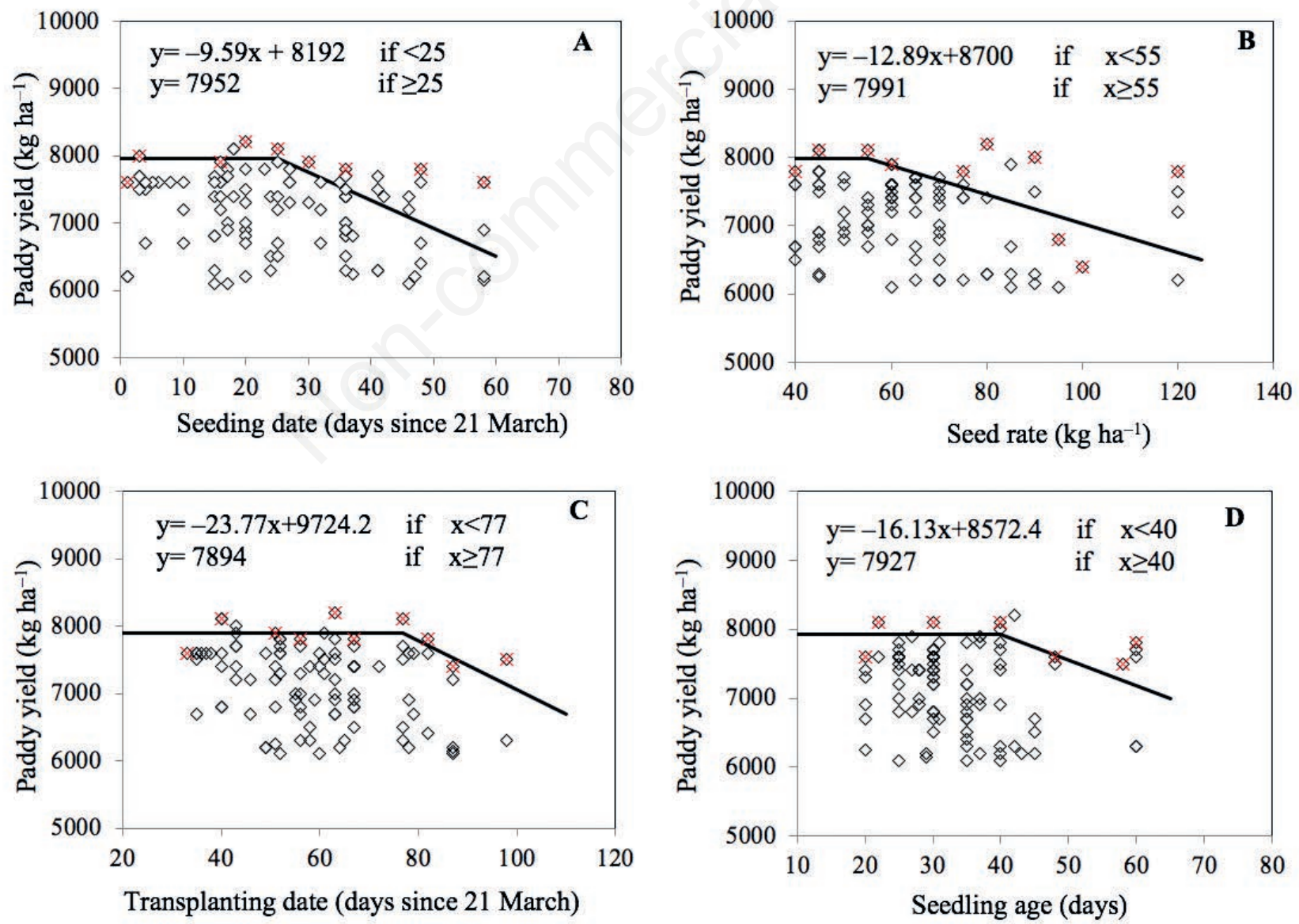

Figure 2. Scatter plots of paddy yield data $v$ s. A) seeding date, B) seed rate, C) transplanting date, and D) seedling age along with the fitted boundary line. In green vertical line highest paddy yield will be produced. 
yield loss due to not using potassium fertiliser was $8 \%$. For this variable, relative yield and relative yield gap were estimated to be 89 and $11 \%$ respectively (Table 4 ).

The results of BLA for plant lodging, pests, diseases, and weeds problem were ranked as none (0), low (1), medium (2), high (3), and very high (4). The results show that the minimum optimal level for these four variables was equal to one. The percentage value of paddy fields outside the optimal range for these four variables were $19 \%, 89 \%, 84 \%$, and $6 \%$, respectively (Table 4 ). The optimum yield value for these four variables was 7990, 8190, 8050 , and $7700 \mathrm{~kg} \mathrm{ha}^{-1}$ respectively. Farmers reached 90\%, 88, 89 and $93 \%$ of the potential yield. Regarding the average farmers yield, the yield gaps were equal to $7.61 \%, 9.48 \%, 8.17 \%$, and $4.89 \%$. The relative yield value of plant lodging, pest, disease, and weed problems were $89.84 \%, 87.64 \%, 89.17 \%$, and $93.22 \%$ respectively. Furthermore, the relative yield gaps of these four variables were $10.16 \%, 12.36 \%, 10.83 \%$, and $6.78 \%$ respectively. According to the boundary line analysis, the average yield based on the optimal level of 13 studied varieties was $7999 \mathrm{~kg} \mathrm{ha}^{-1}$ with a yield gap of $874 \mathrm{~kg} \mathrm{ha}^{-1}$. The average relative yield and relative yield gap of the 13 investigated variables were $89.75 \%$ and $10.25 \%$ respectively (Table 4 ).
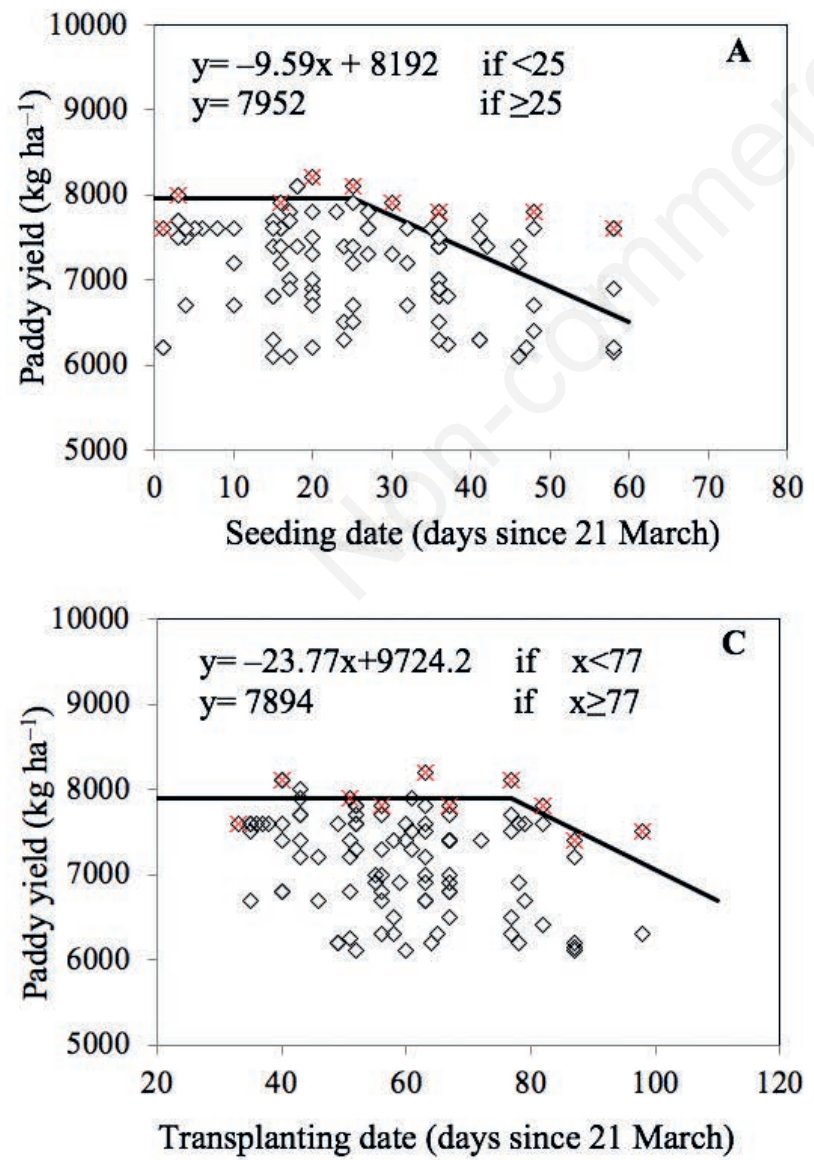

\section{Discussion}

The effort to quantify yield gap requires appropriate methods. To reduce the yield gap in a given area, detection of involved management operations is necessary (van Ittersum et al., 2013). One another important implication of yield gap removal via optimising crop management practice is that optimal crop management may also be significantly cleaner for the environment. Optimal crop management may decrease required input and may lead to less environmental burdens and less pressure on the natural resources (Foley et al., 2011; Smith, 2013; Soltani et al., 2013, 2014). Paoki et al. (2017) revealed that, in wheat and in the same region, a better crop management scenario needed lower nitrogen fertiliser, lower total NPK fertiliser and less input energy, resulted in greater crop yield.

According to the findings of CPA method, the high level of yield gap and the contribution of each factor affecting it show that with proper management, a significant portion of this gap can be offset. The potential yield is rarely achieved in crops, and in practice only part of it is taken as a real crop from the field. Although the purpose of this study was to estimate the rice yield gap in the eastern Mazandaran province, and the reasons for the occurrence
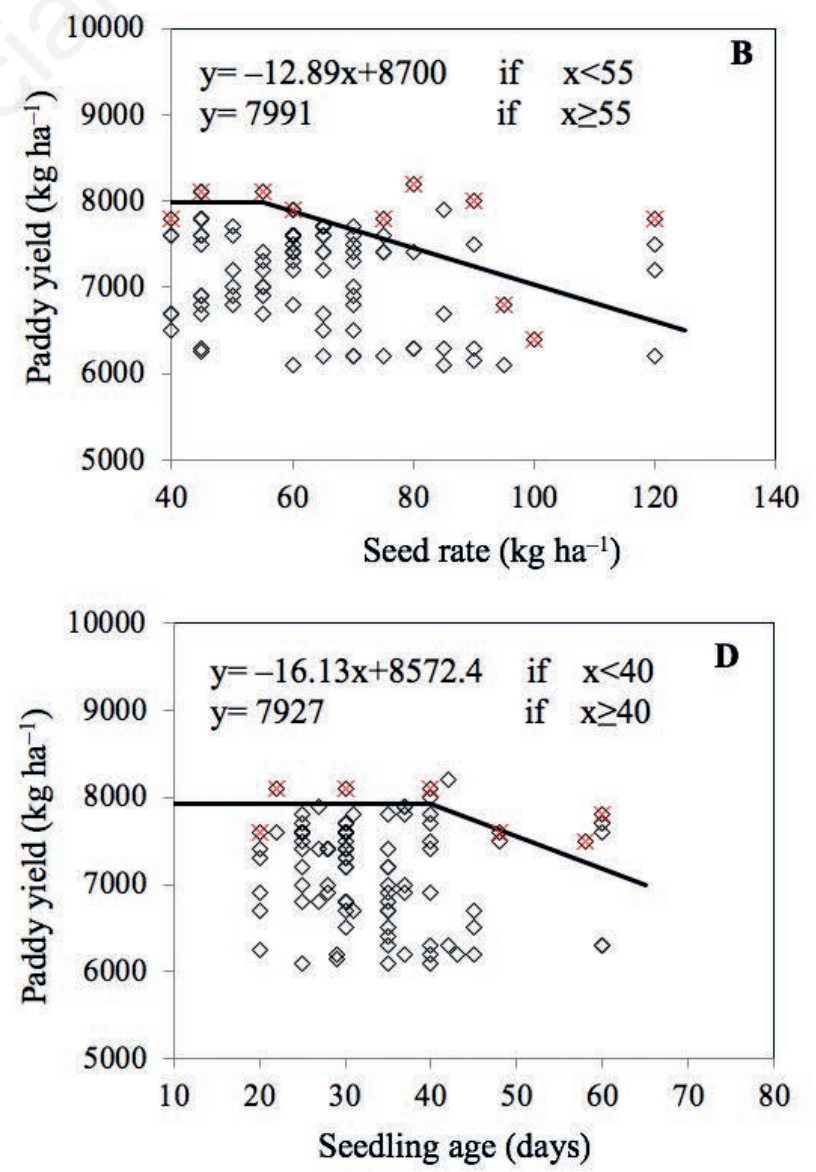

Figure 3. Scatter plots of paddy yield data $v s$. A) seedling frequency per hill, B) planting density, C) total applied nitrogen (kg N.ha ${ }^{-1}$ ), and D) applied potassium $\left(\mathrm{kg} \mathrm{K}_{2} \mathrm{O} \cdot \mathrm{ha}^{-1}\right)$ along with the fitted boundary line. 
of this gap requires further study, the most likely solution that can lead to increased yields and reduced yield gap is by improving crop management in the farmers' fields.

Using BLA method in yield gap studies can clearly show yield responses to agricultural practices and estimate potentials. The interpretation of the results of BLA is simple and it is recommended that a dataset be treated with several analytical methods, along with which boundary line analysis can be used as an applied analysis. It also seems that this analysis can reduce the need for conventional field experiments and provide the investigator with the ability to design new field experiments. If such field surveys are carried out extensively over several years for important crops, it is possible to use more than the ability of such analyses to find ways to increase production. With all these interpretations, it can be said that the calculated yield gap in this study is close to the definition of the yield gap being utilised and shows the difference between the actual and attainable yield values in relation to the environmental conditions of the area. One of the limitations of this research is the number of years covered; the more years taken to complete a study, the more accurate is the estimation of the impact of climate and climate changes. To reduce the yield gap, specifying the yield limits in a particular area is necessary (van Ittersum et al., 2013). The boundary line analysis used in this study in addition to estimating the yield gap indicates the reasons for this yield limitation. The fact that the potential yield calculated in this analysis is obtained from actual data shows that potential yield is dependent on the region; it can be said that this potential yield is attainable. In fact, multi-regional studies impose the effects of planting date, harvesting date, climate and different soil conditions on the plant (van Ittersum et al., 2013). However, there are no such limitations on the potential yield at a research station or in the simulation of potential yield with plant models. Generally, the results of this study indicate that the use CPA and BLA methods in yield gap estimation can properly illustrate the responses of yield to managerial factors by identifying the share of each agricultural variable. Using these responses, researchers can determine the best management and planning to achieve the highest yield. Of course, the use of BLA method has a disadvantage the interaction of variables affecting yield is considered non-significant and only analyses the impact of a variable on yield, while in reality, the yield is the result of the interaction of a set of factors (Kitchen et al., 2003). It is important to note that the use of other methods for estimating potential yield such as the use of plant models along with boundary line analysis can reveal important points of production constraints in a region.

Experiments by various researchers reveal that potential yield is highly sensitive to planting date and cultivar selection in terms of maturity, which together determine the timing of key growth stages and crop-growing season length (Cassman et al., 2010). By estimating yield potential in temperate high-yielding direct-seeded US rice production systems, Epse et al. (2016a) reveal that ORYZA rice crop model simulates potential yield well, with most top yields falling within $85 \%$ of potential yield for both M-206 and $\mathrm{CXL}_{745}$ cultivars. Also, by yield gap analysis of US rice production systems show that there are opportunities for improvement and that potential yield ranged from 11.5 to $14.5 \mathrm{t} \mathrm{ha}^{-1}$, while actual yields varied from 7.4 to $9.6 \mathrm{tha}^{-1}$, or $58-76 \%$ of potential yield (Epse et al., 2016b). From all these interpretations, it can be said that the yield gap calculated in this research is close to the definition presented by Connor et al. (2011) regarding about exploitable yield gap and shows the difference between actual yield and attainable yield in regard to regional environmental conditions. One limitation of this research was the number of years of its implementation. A simulation study done globally for main crops such as corn, wheat, and rice showed a rice yield gap of about $29 \%$ internationally; however, the calculated yield gap was estimated to be 11.0714.73\% (Mueller et al., 2012). Further, van Ittersum et al. (2013) state that although environmental condition and management $\left(\mathrm{G}^{\prime} \mathrm{E}^{\prime} \mathrm{M}\right)$ are beneficial for calculating attainable yield in one specific region and by considering the best combination of genotypes, it is impossible to be sure of non-existent live or dead tension throughout plant growing period. Thus, this yield is not sufficiently suitable for the estimation of region potential regarding climatic and earth conditions in most regions. Specific climatic parameters in the region can also be restricting factors of maximum yield in this study for instance; the amount of seasonal radiation in each region causes the increase or decrease in potential yield.

\section{Conclusions}

The findings show that farmers in the region are unaware of the importance of seedling age, crop rotation, nitrogen splitting (especially in the flowering stage), $\mathrm{K}_{2} \mathrm{O}$ usage by splitting, micronutrient application, and manures usage, which indicates a need to promote and extend scientific findings. In this research, among all the agricultural management practices of the farmers, the cases that have a greater impact on the yield gap and the need for improvement in the first phase are mentioned. Therefore, the advisory recommendation of this study is complementary to other recommended and commonly used management practices.

\section{References}

Banneheka B, Dhanushika M, Wijesuriya W, Herath K, 2013. A linear programming approach to fitting an upper quadratic boundary line to natural rubber data. J. Natl. Sci. Found. Sri. 41:13-20.

Beza E, Silva JV, Kooistra L, Reidsma P, 2017. Review of yield gap explaining factors and opportunities for alternative data collection approaches. Eur. J. Agron. 82:206-22.

Cassman KG, Grassini P, van Wart J, 2010. Crop yield potential, yield trends and global food security in a changing climate. In: Rosenzweig, C., Hillel, D. (Eds.), Handbook of Climate Change and Agro-ecosystems. Imperial College Press, London, p. 37.

Connor DJ, Loomis RS, Cassman KG, 2011. Crop ecology: productivity and management in agricultural systems. Cambridge University Press, 556 p.

Delmotte S, Tittonell P, Moureta JC, Hammonda R, Lopez-Ridaura S, 2011. On farm assessment of rice yield variability and productivity gaps between organic and conventional cropping systems under Mediterranean climate. Eur. J. Agron. 35:223-36.

FAO, 2016. Faostat-Trade/Crops and livestock products. Available from: http://faostat3.fao.org/browse/T/TP/E Accessed: 15 April 2016.

Farooq M, Kobayashi N, Wahid A, Ito O, Basra SMA, 2009. Strategies for producing more rice with less water. Adv. Agron. 101:351-88.

Foley JA, Ramankutty N, Brauman KA, Cassidy ES, Gerber JS, Johnston M, Mueller ND, O'Connell C, Ray DK, West PC, Balzer C, Bennett EM, Carpenter SR, Hill J, Monfreda C, Polasky S, Rockstrom J, Sheehan J., Siebert S, Tilman D, Zaks DPM, 2011. Solutions for a cultivated planet. Nature. 478:337-42. 
Hochman Z, Gobbett D, Holzworth D, McClelland T, van Rees H, Marinoni O, Garcia JN, Horan H, 2013. Reprint of "Quantifying yield gaps in rain-fed cropping systems: A case study of wheat in Australia”. Field Crops Res. 143:65-75.

Hocking RR, 1976. The analysis and selection of variables in linear regression. Biometrics. 32:1-49.

Huang X, Wang L, Yang L, Kravchenko AN, 2008. Management Effects on relationships of crop yields with topography represented by wetness index and precipitation. Agron J. 100:1463.

Kitchen NR, Drummond ST, Lund ED, Sudduth KA, Buchleiter GW, 2003. Soil electrical conductivity and topography related to yield for three contrasting soil-crop systems. Agron. J. 95:483-95.

Liu Z, Yang X, Lin X, Hubbard KG, Lv S, Wang J, 2016. Narrowing the agronomic yield gaps of maize by improved soil, cultivar, and agricultural management practices in different climate zones of Northeast China. Earth Interact. 20:1-18.

Makowski D, Dore T, Monod H, 2007. A new method to analyse relationships between yield components with boundary lines. Agron. Sustain. Dev. 27:119-28.

Milne AE, Ferguson RB, Lark RM, 2006. Estimating a boundary line model for a biological response by maximum likelihood. Ann. appl. Biol. 149:223-34.

Ministry of Jihad-e-Agriculture of Iran, 2016. Annual Agricultural Statics. Available from: www.maj.ir

Mueller ND, Gerber JS, Johnston M, Ray DK, Ramankutty N, Foley JA, 2012. Closing yield gaps through nutrient and water management. Nature. 490:254-7.

Patrignani A, Lollato RP, Ochsner TE, Godsey CB, Edwards JT, 2014. Yield gap and production gap of rain-fed winter wheat in the southern Great Plains. Agron. J. 106:1329-39.

Reidsma P, Jeuffroy MH, 2017. Farming systems analysis and design for sustainable intensification: new methods and assessments. Eur. J. Agron. 82:203-5.

Riffel JD, 2012. Yield response and economic impact of variablerate nitrogen applications in grain sorghum. M.Sc. Thesis of Kansas State University. 115 p.

SAS, 2008. SAS/STAT software, version 9.2 of the SAS system for windows. SAS Institute Inc., Cary, NC, USA.
Schnug E, Heym J, Achwan F, 1996. Establishing critical values for soil and plant analysis by means of the boundary line development system (Bolides). Commun. Soil Sci. Plant Anal. 27:2739-48.

Shatar TM, McBratney AB, 2004. Boundary-line analysis of fieldscale yield response to soil properties. J. Agric. Sci. 142:553-60.

Silva JV, Reidsma P, Laborte AG, van Ittersum MK, 2017. Explaining rice yields and yield gaps in Central Luzon, Philippines: an application of stochastic frontier analysis and crop modeling. Eur. J. Agron. 82:223-41.

Smith P, 2013. Delivering food security without increasing pressure on land. Global Food Secur. 2:18-23.

Soltani A, Hajjarpoor A, Vadez V, 2016. Analysis of chickpea yield gap and water-limited potential yield in Iran. Field Crops Res. 185:21-30.

Soltani A, Maleki MHM, Zeinali E, 2014. Optimal crop management can reduce energy use and greenhouse gases emissions in rainfed canola production. Int. J. Plant Prod. 8:587-604.

Soltani A, Rajabi MH, Zeinali E, Soltani E, 2013. Energy inputs and greenhouse gases emissions in wheat production in Gorgan, Iran. Energy. 50:54-61.

Tanaka A, Diagne M, Saito K, 2015. Causes of yield stagnation in irrigated lowland rice systems in the Senegal River Valley: application of dichotomous decision tree analysis. Field Crops Res. 176:99-107.

Tanaka A, Saito K, Azoma K, Kobayashi K, 2013. Factors affecting variation in farm yields of irrigated lowland rice in southern-central Benin. Eur. J. Agron. 44:46-53.

Tasistro A, 2012. Use of boundary lines in field diagnosis and research for Mexican farmers. Better Crops Plant Food. 96:11-3.

van Ittersum MK, Cassman KG, Grassini P, Wolf J, Tittonell P, Hochman Z, 2013. Yield gap analysis with local to global relevance-A review. Field Crops Res. 143:4-17.

Webb RA, 1972. Use of the boundary line in the analysis of biological data. J. Hortic. Sci. 47:309-19.

Xu X, He P, Zhao S, Qiu S, Johnstond AM, Zhou W, 2016. Quantification of yield gap and nutrient use efficiency of irrigated rice in China. Field Crops Res. 186:58-65. 